\title{
Monocyte/macrophage and T-cell infiltrates in peritoneum of patients with ovarian cancer or benign pelvic disease Xipeng Wang ${ }^{1}$, Michael Deavers², Rebecca Patenia ${ }^{3}$, Roland L Bassett Jr ${ }^{4}$, Peter Mueller ${ }^{4}$, Qing Ma ${ }^{5}$, Ena Wang ${ }^{6}$ and Ralph S Freedman*3
}

\begin{abstract}
Address: ${ }^{1}$ Department of Obstetrics and Gynecology, Renji Hospital, Shanghai Tiao Tong University, Shanghai, China, ${ }^{2}$ Department of Pathology, The University of Texas M. D. Anderson Cancer Center, Houston, Texas, USA, ${ }^{3}$ Department of Gynecologic Oncology, The University of Texas M. D. Anderson Cancer Center, Houston, Texas, USA, ${ }^{4}$ Department of Biostatistics and Applied Mathematics, The University of Texas M. D. Anderson Cancer Center, Houston, Texas, USA, ${ }^{5}$ Department of Blood and Marrow Transplantation, The University of Texas M. D. Anderson Cancer Center, Houston, Texas, USA and ' Department of Transfusion Medicine, National Institutes of Health, Bethesda, Maryland, USA
\end{abstract}

Email: Xipeng Wang - xipengwang@yahoo.com; Michael Deavers - mdeavers@mdanderson.org; Rebecca Patenia - rpatenia@mdanderson.org; Roland L Bassett - rlbasset@mdanderson.org; Peter Mueller - pm@odin.mdacc.tmc.edu; Qing Ma - qma@mdanderson.org; Ena Wang - ewang@cc.nih.gov; Ralph S Freedman* - rfreedma@mdanderson.org

* Corresponding author

Published: 06 July 2006

Journal of Translational Medicine 2006, 4:30 doi:10.1 186/1479-5876-4-30
Received: 24 May 2006

Accepted: 06 July 2006

This article is available from: http://www.translational-medicine.com/content/4/I/30

(c) 2006 Wang et al; licensee BioMed Central Ltd.

This is an Open Access article distributed under the terms of the Creative Commons Attribution License (http://creativecommons.org/licenses/by/2.0), which permits unrestricted use, distribution, and reproduction in any medium, provided the original work is properly cited.

\begin{abstract}
Background: We previously showed that tumor-free peritoneum of patients with epithelial ovarian cancer (EOC) exhibited enhanced expression of several inflammatory response genes compared to peritoneum of benign disease. Here, we examined peritoneal inflammatory cell patterns to determine their concordance with selected enhanced genes.

Methods: Expression patterns of selected inflammatory genes were mined from our previously published data base. Bilateral pelvic peritoneal and subjacent stromal specimens were obtained from 20 women with EOC and 7 women with benign pelvic conditions. Sections were first stained by indirect immunoperoxidase and numbers of monocytes/macrophages (MO/MA), T cells, B cells, and NK cells counted. Proportions of CD68+ cells and CD3+ cells that coexpressed MO/MA differentiation factors (CDI63, CCRI, CXCR8, VCAMI, and phosphorylated cytosolic phospholipase $\mathrm{A}_{2}\left[\mathrm{pcPLA} \mathrm{A}_{2}\right]$ ), which had demonstrated expression in EOC peritoneal samples, were determined by multicolor immunofluorescence.

Results: MO/MA were present on both sides of the pelvic peritoneum in EOC patients, with infiltration of the subjacent stroma and mesothelium. CD68+ MO/MA, the most commonly represented population, and CD3+ T cells were present more often in EOC than in benign pelvic tumors. NK cells, B cells, and granulocytes were rare. CXCL8 (IL-8) and the chemokine receptor CCRI were coexpressed more frequently on MO/MA than on CD3+ cells contrasting with CD68+/CDI63+ cells that coexpressed CXCL8 less often. An important activated enzyme in the eicosanoid pathway, pcPLA ${ }_{2}$, was highly expressed on both CD68+ and CDI63+ cells. The adherence molecule Vascular Cell Adhesion Molecule-I (VCAMI) was expressed on CD3I+ endothelial cells and on a proportion of CD68+ MO/MA but rarely on CD3+ cells.
\end{abstract}

Conclusion: The pelvic peritoneum in EOC exhibits a general pattern of chronic inflammation, represented primarily by differentiated MO/MA, and distinct from that in benign conditions concordant with previous profiling results. 


\section{Background}

Epithelial ovarian cancer (EOC) results in 5 year survival rates of only $25-30 \%$ for patients with stage III and IV disease [1], contrasting with the $90 \%$ survival rates of patients with stage I disease, where notably peritoneal and serosal disease is absent. It is perhaps a paradox that the peritoneum which is organized to protect the integrity of intraabdominal organs by facilitating infiltration of inflammatory cells to sites of injury and infection, might also serve to facilitate the promotion of tumor growth and spread.

As EOC advances and penetrates the capsular layer of the ovary, it also carries the potential to expose the peritoneal surface to tumor-cell secreted products. The peritoneum and its extension, the intestinal serosa, include a vast surface area for transit of inflammatory cells into the abdominal cavity. Its surface mesothelium and submesothelial stroma and structure pose no substantial barriers to inflammatory modulatory cytokines, chemokines and other molecules produced by the tumor or its metastasis, at least to a depth of approximately $1 \mathrm{~mm}$ [2]. The stroma consists of a collagen-based matrix, blood vessels, lymphatics, nerve fibers, and rare hematogenous cells $[3,4]$. Surgery for EOC often reveals changes in the non-tumorbearing peritoneum such as thickening or edema, enhanced vascular patterns, and soft or firm adhesions [5]. The peritoneum and intestinal serosa may have a florid appearance similar to that found in peritonitis. Despite this evidence of inflammation, the inflammatory process in the peritoneum of patients with EOC has not been adequately described or characterized.

Using a previously validated cDNA microarray platform consisting of 17,500 clones enriched with inflammatory and immunologically relevant genes [6-8], we previously showed that the gene profiles of the pelvic peritoneum in patients with EOC exhibited a pattern consistent with the presence of $\mathrm{MO} / \mathrm{MA}$ differentiation, activation, and cell survival and that the pattern was different from that of the peritoneum of patients without cancer or that of the tumor itself [9]. Categorizing genes on the basis of annotated gene function led to our observing that genes associated with inflammation were overexpressed in non-tumor bearing peritoneum of patients with ovarian cancer as compared with the peritoneum of patients with benign ovarian tumors.

The purpose of the study reported here was to describe the global pattern of the main inflammatory cell populations in the peritoneum and stroma and to determine whether the magnitude of expression of a limited group of inflammatory genes could be confirmed at the cellular proteomic level in peritoneal tissue and ascites cells.

\section{Methods}

Peritoneal and subjacent stromal biopsy specimens were obtained from 20 patients with EOC and from 7 patients with benign ovarian or other pelvic tumors who underwent surgery at M. D. Anderson Cancer Center according to a protocol approved by the appropriate institutional review board. Demographic characteristics of those patients are shown in Table 1. Biopsy samples were obtained from the peritoneum and from the submesothelial stroma on both sides of the pelvis, approximately 2 $\mathrm{cm}$ from the nearest visible tumor deposits, as quickly as possible after the abdominal cavity was accessed. Peritoneal biopsy samples were obtained carefully without prior manipulation of the chosen biopsy sites to minimize artifact induced variability. As controls, specimens were obtained from similar peritoneal sites in consenting subjects who were undergoing pelvic abdominal surgery but who did not have a diagnosis of cancer. The combined thickness of the peritoneal and separately obtained deeper stromal biopsy specimens was estimated at 1-2 millimeters. A technician was present in the operating room to receive and process all biopsy specimens. All specimens were bisected. One portion, for histopathologic, immunohistochemical, and immunofluorescence costaining, was collected and transported to the lab on ice where it was snap-frozen in Polyfreeze Tissue Freezing Medium (Polysciences, Warrington, PA). Another portion, to be used for microarray, was placed in a sterile tube containing $5 \%$ dextrose $0.2 \%$ sodium chloride solution and transported on ice to the laboratory. The tissue was removed from the saline solution and snap-frozen in a vial with RNAlater (Ambion, Austin, TX) to minimize RNA metabolism and degradation. Subsequently, peritoneal tissue was also obtained from several additional patients for eicosanoid studies. This tissue was placed dry into a sterile tube and snap-frozen in liquid nitrogen in the operating room. All tissues were stored at $-80^{\circ} \mathrm{C}$. Benign cases included: ovarian fibrothecoma (3), serous cystoadenoma or cystoadenofibroma (3), and ovarian papillary proliferation (1). A gynecologic pathologist (M.D.) reviewed all hematoxylin-and-eosin (H\&E) stained sections from specimens used in this study. Peritoneal specimens showing microscopic tumor involvement were not included in the studies described here.

\section{Immunohistochemical staining of peritoneal biopsy tissues Indirect immunoperoxidase (IIP) staining}

To determine the proportions of infiltrating mononuclear leukocyte populations in the peritoneal stroma, cryopreserved peritoneal biopsy specimens were cut and stained, using an avidin-biotin immunoperoxidase method $[10,11]$. IIP staining is generally considered more sensitive and specific than $\mathrm{H} \& \mathrm{E}$ for staining and identifying mononuclear leukocyte populations in cryopreserved tissue. Briefly, $6-\mu \mathrm{m}$ sections of cryopreserved peritoneal tissues 
Table I: Clinical characteristics of the 20 chemo-naive patients with epithelial ovarian cancer

\begin{tabular}{ll}
\hline Characteristics & $N(\%)$ \\
\hline Mean Age, years (range) & $60(36-79)$ \\
$\quad$ Patients with malignant disease $(\mathrm{n}=20)$ & $64(47-83)$ \\
$\quad$ Patients with benign ovarian disease $(\mathrm{n}=7)$ & $10(50 \%)$ \\
EOC Histology & $2(10 \%)$ \\
Serous & $2(10 \%)$ \\
Mucinous & $1(5 \%)$ \\
Endometrioid & $5(25 \%)$ \\
Clear cell & \\
Mixed & $2(10 \%)$ \\
Disease Stage & $18(90 \%)$ \\
I- II & \\
III - IV & $2(10 \%)$ \\
Tumor Grade & $2(10 \%)$ \\
I & $16(80 \%)$ \\
II & \\
III & $11(55 \%)$ \\
Surgical Debulking & $9(45 \%)$ \\
Optimal & \\
Suboptimal & \\
\hline
\end{tabular}

were immediately fixed with acetone for 10 minutes, airdried for 30 minutes, and then kept at $20^{\circ} \mathrm{C}$ overnight. Sections were then air-dried for another 30 minutes at room temperature and endogenous peroxidase activity was blocked by incubation in $0.3 \% \mathrm{H}_{2} \mathrm{O}_{2}$ in PBS for 15 minutes. Sections were then washed three times in PBS, and nonspecific reactions were blocked with $2 \%$ normal horse serum for 30 minutes. Sections were then incubated for 2 hours at room temperature with the primary antibodies as follows. For the immunohistochemical analyses, primary antibodies were: Mouse anti-human CD45 leukocyte common antigen [LCA] clones 2B11 + PD7/26, catalog no. M0701, Mo IgG1, 1/400 (DakoCytomation, Carpinteria, CA); mouse anti-human CD3 clone T3-4B5, catalog no. M0756, Mo IgG1, 1/225 (DakoCytomation); mouse monoclonal antibody KP1 to CD68, catalog no. ab955, Mo IgG1, 1/2000 (Abcam, Cambridge, MA); mouse anti-SCLC (CD56, N-CAM) clone 123C3. Mo IgG1, 1/50 (Zymed Labs, San Francisco, CA); and mouse anti-human CD20 clone B-LyI, catalog no. M0774, Mo IgG1 kappa 1/700 (DakoCytomation). Secondary antibodies used were: biotinylated horse anti-mouse IgG (1:200) (Vector Laboratories, Burlingame, CA); Universal LSAB kit/HRP Rabbit/Mouse, catalog no. K0675 (DakoCytomation), and appropriate isotype controls. Optimal conditions for staining with each antibody were determined by using appropriate test tissues. After being washed with PBS three times, sections were incubated with the appropriate secondary antibody for 1 hour at room temperature. Sections were then washed again with
PBS and incubated with avidin-biotin peroxidase conjugate (ABC Kit, Vector Laboratories, catalog no. PK6102) at a dilution of 1:100 for 30 minutes at room temperature, after which AEC substrate (Vector Laboratories, catalog no. SK-4200) was added for 10 minutes. Sections were washed with tap water, counterstained with Vector hematoxylin (Vector Laboratories) for 1 minute, and mounted with permanent aqueous mounting medium (Biomeda, Foster City, CA, catalog no. M03) [10].

Coded slides for indirect immunoperoxidase staining were counted in nine areas per tissue section by random field selection, and the number of cells was averaged per $0.08 \mathrm{~mm} 2$. Distributions and ratios of $\mathrm{MO} / \mathrm{MA}$ and T cells were determined by quantitative immunochemical analysis with a Leica DM LB (Leica, Germany) image analyzer equipped with Image Pro Plus software (Media Cybernetics, Silver Springs, MD) [9]. The Image ProPlus software program evaluates random counting of positive cells by using a grid mask in the process menu, and artifacts are removed by using the delete option.

Multi antibody immunofluorescence costaining and confocal microscopy of peritoneal biopsy specimens

In situ cell populations or subsets were examined by multicolor immunofluorescence costaining to detect surface receptors and certain cytoplasmic proteins that had been identified in our previous transcriptome studies $[9,12]$. For the experiments described here, CCR1, CXCL8 (IL-8), CD163, and VCAM1 were included for costaining mono- 
nuclear leukocytes that expressed CD68+ or CD3+. In some experiments, $\mathrm{MO} / \mathrm{MA}$ and the $\mathrm{CD} 163+$ subset were costained with phosphorylated cytosolic phospholipase 2 (cPLA2), which together with sPLA2 (Group 2a) was overexpressed in peritoneal samples from EOC patients. Freshly cut tissues $(6 \mu \mathrm{m})$ were fixed in $4 \%$ paraformaldehyde for 20 minutes at room temperature, after which sections were washed in PBS, permeabilized with 0.5\% Triton 100x, blocked with 5\% normal goat serum, and incubated with primary antibodies overnight at $4^{\circ} \mathrm{C}$.

\section{IIF triple costaining}

A sequential staining technique was used for this method as follows: 3 hours incubation with the first primary antibody (red) at RT, overnight incubation with the second primary antibody (blue) at $4{ }^{\circ} \mathrm{C}$, and 3 hours incubation with the third primary antibody at RT. Secondary antibodies were incubated with the sections for 1 hour after the incubations with the primary antibodies were complete. Nonspecific binding was blocked by adding 5\% normal goat serum for 1 hour. The primary antibodies used were: mouse anti-human CD3 clone T3-4B5, Mo IgG1 kappa, 1:225 dilution, catalog no. M0756 (DakoCytomation); polyclonal rabbit anti-human CD3, 1:100, catalog no. A0452 (DakoCytomation); mouse anti-human CD68, Mo IgG2a, 1:30, catalog no. MCA1815 (Serotec, Raleigh, NC); mouse monoclonal antibody KP1 to CD68, Mo IgG1 kappa, 1:1500, catalog no. ab955 (Abcam); mouse anti-human CD163, Mo IgG1, 1:100, catalog no. MCA1853 (Serotec); mouse anti-humanVCAM1 clone 1.4C3, Mo IgG1 kappa, 1:50, catalog no. M7106 (DakoCytomation); mouse anti-human CCR1, Mo IgG2B, 1:100, catalog no. MAB145 (R\&D Systems, Minneapolis, MN); mouse anti-human CD14, Mo IgG2a kappa, catalog no. M0825 (DakoCytomation); polyclonal rabbit antihuman IL-8, 1:5, catalog no. AHC0881 (Biosource, Camarillo, CA); phospho-cPLA2 (Ser 505) antibody (rabbit) \#2831, 1:50 (Cell Signaling Technology, Danvers, MA); mouse anti-human CD31 (PECAM-1, Platelet gpIIa Molecule), catalog no. C2383-02, Mo IgG2b, 1:100 (United States Biological, Swampscott, MA); and mouse anti-human cytokeratin clone AE1/AE3, Mo IgG1 kappa, 1:50, catalog no. M3515 (DakoCytomation). The secondary antibodies used depended on the isotype of the primary antibodies, and included Cy2-conjugated (green) AffiniPure goat anti-mouse IgG, Fc $\gamma$ subclass 1-specific, catalog no. 115-225-205; Cy3-conjugated (red) AffiniPure goat anti-rabbit IgG $(\mathrm{H}+\mathrm{L})$, catalog no. 111-165144; Cy5-conjugated (blue) AffiniPure goat anti-mouse IgG, Fc $\gamma$ subclass 2b-specific, catalog no. 115-175-207; Cy5-conjugated (blue) AffiniPure goat anti-mouse IgG, Fc $\gamma$ subclass 2a-specific, catalog no. 115-175-206; Cy3conjugated (red) AffiniPure goat anti-mouse IgG, Fc $\gamma$ subclass 2a-specific (minimal cross-reaction with bovine, and rabbit serum proteins), catalog no. 115-165-206 (all from Jackson ImmunoResearch Laboratories, West Grove, PA). Negative controls employed secondary antibodies alone.

Tissue sections were mounted with Slow-Fade Gold AntiFade reagent (catalog no. S36936, Molecular Probes) and viewed with a Olympus FV500 laser scanning confocal microscope; images were captured at $400 \times$ and $600 \times$ magnification by Fluoview software Version 4.3.

\section{Statistics}

Wilcoxon tests were used to compare the distribution of markers between malignant and benign samples. Paired ttests were used to compare inflammatory cell numbers from each side of the pelvis and between the superficial and deeper stroma.

\section{Results and discussion}

We first examined our data base of more than 50 inflammation-linked genes that have been shown to be expressed differently in malignant and benign peritoneum [9]. The genes in Figure 1 were mined from a database that supported our earlier report on the peritoneal transcriptome [9]. Gene expression levels were generated by centering followed by cluster analysis and displayed as dendrograms (trees) [13]. Here we show expression of several of these genes that encode for the following molecules: CXCL8, a contributor to tumor angiogenesis and leukocyte chemotaxis, CD163 the scavenger molecule associated with MA differentiation, CCR1, a chemokine receptor expressed on different leukocytes, including MA and that binds to multiple CC ligands produced by ovarian cancer cells, and MA, VCAM1, an adherence moledule and ligand for VLA-4 integrin and induced on endothelial cells by tumor necrosis factor (TNF $\alpha$ ), interleukin $1 \alpha$ (IL1 $\alpha$ ) and certain other cytokines. We also detected increased expression of phosphorylated phospholipase A2 (sPLA2), the activated cytosolic form of the protein that releases arachidonic acid from membranes (a critical early step in the eicosanoid pathway) and that can induce CXCL8 (IL-8), IL-6, and CD44 production. Our previous gene profile analysis of the EOC peritoneum suggested that CXCL8 (IL-8) has a central role in these inflammatory cell pathways $[9,12]$. Analysis of the mined data for both sPLA2 (group 2a) and CPLA2 (group 4a) revealed significant differences in transcript levels, being higher in EOC tumor $(n=8)$ or peritoneum $(n=10)$ than in benign peritoneum $(n=5)$. These differences were statistically significant for CPLA2 and SPLA2 respectively in EOC vs benign peritoneum $(\mathrm{P}=0.004)$ and $\mathrm{P}=0.02$ and for both CPLA2 and SPLA2 in EOC tumor vs benign peritoneum $(\mathrm{P}=$ 0.005 for both). The P values were based on a nonparametric rank-sum test for comparing samples with multiple endpoints [14]. 


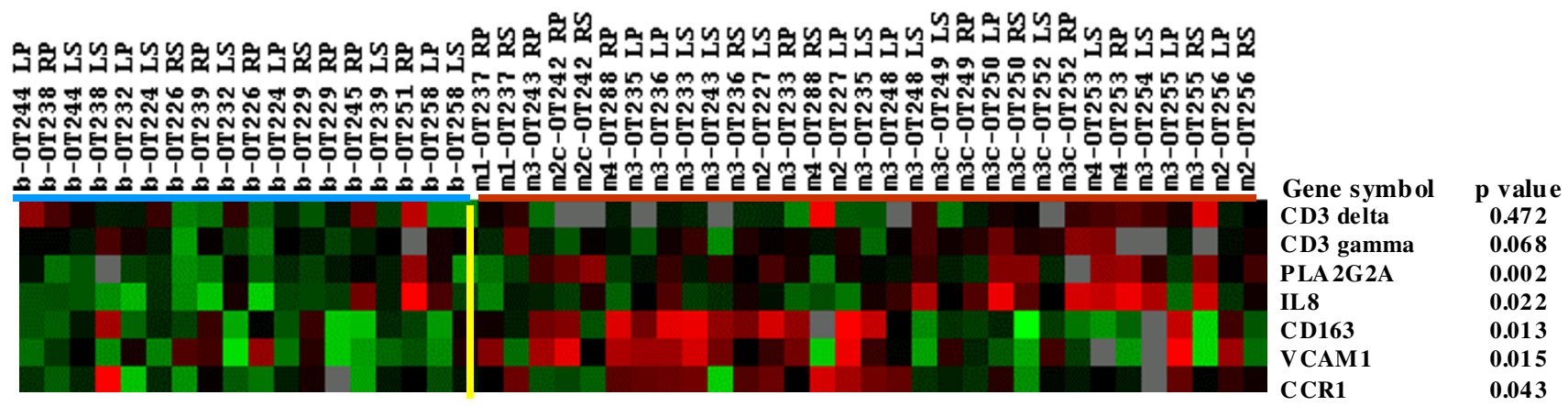

\section{Figure I}

Selected genes expressed at different levels in the peritoneum and stroma of patients with EOC vs in patients with benign pelvic disease. The red bars indicate the malignant phenotype and the blue bars the benign controls. The significance level of each gene expression between benign and malignant phenotypes is presented as $P_{(t 2)}$ values.

Peritoneum biopsy specimens from women with benign pelvic conditions contained fewer leukocytes (Fig. 2) than did peritoneal specimens from patients with EOC, which demonstrated more extensive leukocyte infiltration. Indirect immunoperoxidase staining with anti-CD68 or antiCD3 monoclonal antibodies revealed that the leukocyte infiltrates consisted of two main populations: $\mathrm{MO} / \mathrm{MA}$ (CD68+) and T cells (CD3+). LCA was expressed by most peritoneal tissue leukocytes in both malignant and benign conditions. Other cell populations, including granulocytes, B cells, and NK cells, were rare (data not shown). $\mathrm{CD} 68+(\mathrm{MO} / \mathrm{MA})$ and $\mathrm{CD} 3+$ (T-cell) infiltrates were examined in tumor-free peritoneal tissues from 19 of the 20 patients with EOC (one sample was unsuitable for assessment). The mean number of $\mathrm{MO} / \mathrm{MA}$ per $0.08 \mathrm{~mm}^{2}$ field in the EOC peritoneum was 16.8 and that of $\mathrm{T}$ cells was 11.2 , as compared with $6.4 \mathrm{MO} / \mathrm{MA}$ and $2.6 \mathrm{~T}$ cells per field in benign peritoneum (Table 2). MO/MA were substantially more common than were T cells (Table 2) (P $=0.0002$ by paired t-test $)$. By contrast, the mean numbers of B cells (CD20+) and NK cells (CD56+) were 4.5 and 1.6 per field in the EOC peritoneum respectively but were rarely detected in benign peritoneum.

Numbers of CD68+ and CD3+ cells were also examined in paired samples where peritoneal tissues were available from each side of the pelvis. Paired t tests showed no significant differences between the two sides (Table 3 ). This bilateral presence of $\mathrm{MO} / \mathrm{MA}$ and T-cell infiltrates in the pelvic peritoneum suggests a spatially generalized distribution pattern rather than a site-specific effect. In the 5 EOC cases in which paired superficial (submesothelial and deeper stroma) samples were available for comparison, more CD3+ cells were found near the mesothelial surface than in the deeper stroma $(P=0.020)$. CD68+ cells were present in large numbers at both levels.
We next examined the MO/MA population, our primary focus for this study, at the cellular proteomic level. The monoclonal antibodies (mAbs) used included those that recognize CD163, CCR1, CXCL8, VCAM1 and CPLA2.

In the present experiments, we examined the two main mononuclear cell populations, CD68+ and CD3+, by indirect immunofluorescence costaining using confocal microscopy, for characteristics that would help to identify functional subsets. Because CD68+ cells were the dominant population in the peritoneum, we reasoned that CD68+ cells (or some subset of those cells) could be a major source of the CXCL8 gene expression product in the peritoneum.

Peritoneal biopsy specimens from 7 patients and ascites cytopreparations from 3 patients were tested with tripleantibody staining and evaluated by confocal microscopy. Figure 3 (Row 1) shows surface peritoneum with positive staining for cytokeratin, CD31 (endothelial cells), and CD68. Marked infiltration of CD68+ cells is seen both below and within the surface mesothelium. This is compared with the peritoneum from a patient with a benign condition where only the keratin positive surface mesothelium is shown along with some endothelial cells (Fig. 3 , Row 2). The proportions of CD68+ and CD3+ mononuclear leukocytes that coexpress products of certain genes differentially overexpressed in the peritoneal transcriptome profile (Figure 1) are shown in Table 4. Figure 3 and Table 4 show that CXCL8 (IL8), which appears to have a central position in the peritoneal inflammatory transcriptome, was expressed more often on CD68+ cells than on the CD68+ CD163+ subset. CD163 has been identified specifically on a subset of differentiated $\mathrm{MO} /$ MA, and might have a role in adaptive immunity [15]. To summarize the important observations, CCR1, the chem- 

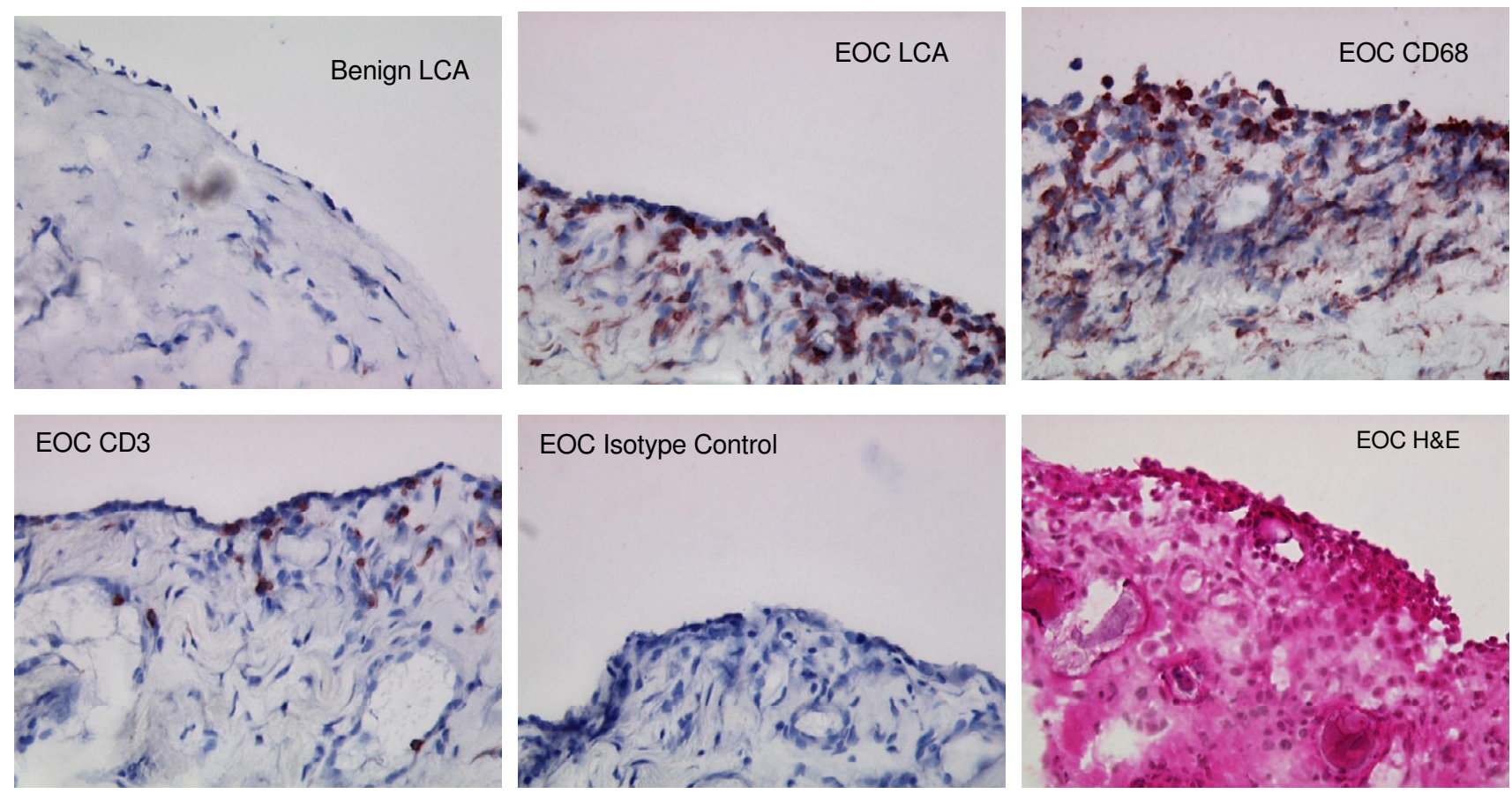

\section{Figure 2}

MO/MA \& T-cell infiltration in peritoneum. Left upper shows peritoneum of patient w/benign fibrothecoma with scant LCA+ leukocytes below the single layer of mesothelium. Remaining 5 panels show tumor-free peritoneum from a patient with EOC. Upper middle shows large number of LCA+ cells; upper right shows large number of CD68+ cells; lower left shows relatively fewer CD3+ cells; lower middle shows negative isotype control; lower right shows H\&E. Magnification---200x

okine receptor that binds to a number of different ligands produced in the environment of EOC was expressed on $60.3 \%$ (range $44-83 \%$ ) of CD68+ cells and on only $15.1 \%$ (range $0-53 \%$ ) of CD3+ cells in the peritoneum. Proportions of CCR 1 expression were $80.7 \%$ and $4 \%$ on ascitic CD68+ and CD3+ cells, respectively. The proportion of CD68+ cells or CD68+ CCR1+ cells that coexpressed CXCL8 was also higher than in the CD3+ or CD3+ CCR1+ populations. These results suggest that peritoneal $\mathrm{MO} / \mathrm{MA}$ might be an important source of CXCL8 in the peritoneal environment of EOC.
We found the proportion of peritoneal $\mathrm{CD} 68^{+}$cells that coexpressed CD163 to vary from $19 \%$ to $78 \%$; cells that were CD68+CD163+CXCL8+ usually contributed less than $10 \%$ of total CD68+ cells (Figure 3, rows $3 \& 4 \&$ Table 4). In the EOC peritoneum, though a higher proportion were present in ascites, CD68+ cells were more often detected within the surface layer of the mesothelium than were CD163+ cells, which seemed to be concentrated below the mesothelial surface. However, in benign conditions, CD163+ cells, though present in smaller numbers, seemed to be more broadly distributed under the mes-

Table 2: Median numbers of immune cells expressing CD3, CD68, and LCA in peritoneal tissue from patients with EOC or benign ovarian tumors

\begin{tabular}{lcccccccccc}
\hline & \multicolumn{3}{c}{ CD3 (T cells) } & \multicolumn{3}{c}{ CD68 (MO/MA) } & & CD45 (LCA) \\
\hline & Left & Right & Average & Left & Right & Average & Left & Right & Average \\
\hline EOC & 7.4 & 9.5 & 8.7 & 14.7 & 15.3 & 15.3 & 17.4 & 18.2 & 18.1 \\
Benign & 1.7 & 2.0 & 1.7 & 7.2 & 4.1 & 5.3 & 3.7 & 4.7 & 4.1 \\
P-value & 0.012 & 0.016 & 0.002 & 0.038 & 0.002 & $<0.001$ & 0.003 & 0.001 & $<0.001$ \\
\hline
\end{tabular}

Values are expressed as median absolute numbers of cells per $0.08-\mathrm{mm}^{2}$ field.

MO/MA, monocytes/macrophages; LCA, leukocyte common antigen. 
Table 3: The comparison of immune cells with positive CD3, CD68, and LCA markers between left and right sides in patients with EOC.

\begin{tabular}{|c|c|c|c|c|}
\hline Marker and Location & No. of Samples & & $\begin{array}{l}\text { Average Difference (Left - } \\
\text { Right) }\end{array}$ & P Value \\
\hline \multicolumn{5}{|l|}{ CD3 } \\
\hline Peritoneum & 15 & Median & -0.33 & 0.89 \\
\hline Stroma & 5 & Median & -2.40 & 0.42 \\
\hline \multicolumn{5}{|l|}{ CD68 } \\
\hline Peritoneum & 15 & Median & 0.57 & 0.84 \\
\hline Stroma & 5 & Median & 0.10 & 0.97 \\
\hline \multicolumn{5}{|l|}{ LCA } \\
\hline Peritoneum & 15 & Median & 1.27 & 0.77 \\
\hline Stroma & 5 & Median & -4.90 & 0.29 \\
\hline
\end{tabular}

othelium. The antibody to CD68 used here recognizes a lysozyme marker that can sometimes be coexpressed by keratin-positive epithelial cells [16]. Some large lymphoblastoid T-cells may also coexpress CD68, as suggested by the presence of large ascitic mononuclear cells showing surface staining for CD3 and cytoplasmic staining for the CD68 antigen. CD3 costaining with $\mathrm{CD}^{+} 8^{+}$or with CD163+ was rarely observed in the peritoneum, supporting the specificity of the antibody staining for T cells, total $\mathrm{MO} / \mathrm{MA}$, and the CD163+ MO/MA subset. CXCL8 was expressed on the surface epithelium in both malignant and benign conditions (data not shown), suggesting that CXCL8, even at low levels, may have a functional role in the absence of cancer.

VCAM1, an important adhesion molecule, was also expressed primarily by $\mathrm{CD} 68^{+}$cells $(53 \%)$ and by CD $31^{+}$ endothelial cells but only infrequently by $\mathrm{CD}^{+}$cells (3.6\%) (Table 4). Finally, CD68+ cells and the CD163+ subset in both peritoneal and ascitic cells also expressed substantial amounts of pcPLA2 (Figure 4). However, the pattern of pcPLA2 expression both in the peritoneum and in ascitic cells seemed to differ between the total population of $\mathrm{CD}^{+} 8^{+}$cells and the CD163+ cells; CD68+ cells showed both cytoplasmic and nuclear staining, and CD163+ cells showed costaining of pcPLA2 only in the nucleus.

\section{Conclusion}

Collectively, our results represent the first steps in showing that inflammatory cells have a spatially generalized distribution pattern in the pelvic peritoneum of EOC and that the inflammatory cell subsets are both quantitatively and qualitatively different from the patterns typical of benign pelvic disease. These findings complement those of our previous study of the EOC peritoneal transcriptome [9] and could suggest a common biologic effect. The inflammatory cell infiltrates in cancer could contribute to antitumor effects or, conversely, promote invasion and metastasis. Our previous studies $[17,18]$ suggest that ascitic MO/MA, representing a substantial proportion of the intraperitoneal inflammatory cell environment, include cells that exhibit defective Fc $\gamma$ R [18]mediated activity or mediate $\mathrm{T}$ cell suppressor functions[17]. Here we showed that tissue from nontumor-involved peritoneum in patients with EOC exhibited substantial leukocyte infiltrates in comparison with peritoneal tissues in patients with benign pelvic disease and that the infiltrate consisted mainly of $\mathrm{MO} / \mathrm{MA}$ and, to a lesser extent, T cells. Other cells (NK [CD56+] and B cells [CD20+]) were found, but in much lower numbers. These results lead us to speculate that MO/MA and T-cell infiltrates in the peritoneum were responding to a general migration stimulating effect; given their proximity to the peritoneal cavity, the large numbers of $\mathrm{MO} / \mathrm{MA}$ and $\mathrm{T}$ cells found in ascitic fluid could well have originated from cells that had migrated into the submesothelial stroma from an extensive network of small capillary vessels, facilitated by expression of adhesion molecules in the capillary endothelium. These views are consistent with the work of Alberto Mantovani $[19,20]$ who has demonstrated the effect of tumor cell products on the "polarization" of MA. In our studies on the peritoneum, we found substantial numbers of CD68+ cells, and CD68+ CD163+ cells, to be concentrated near the mesothelium. The CD68+ CD163population in particular appeared more likely to coexpress CXCL8, a proangiogenic chemokine that can influence the migration of different leukocyte populations. The presence of CD68 cells within the mesothelial cell layer also suggests that these cells are in transit to the peritoneal cavity compartment or ascitic fluid.

A number of chemokines might contribute to the migration and activation of leukocytic as well as other cells in the EOC environment. Migration effect is dependent largely on the expression of complementary receptors of ascites for a number of CC or CXC chemokines (named for the arrangement of their first two cysteine residues). As 

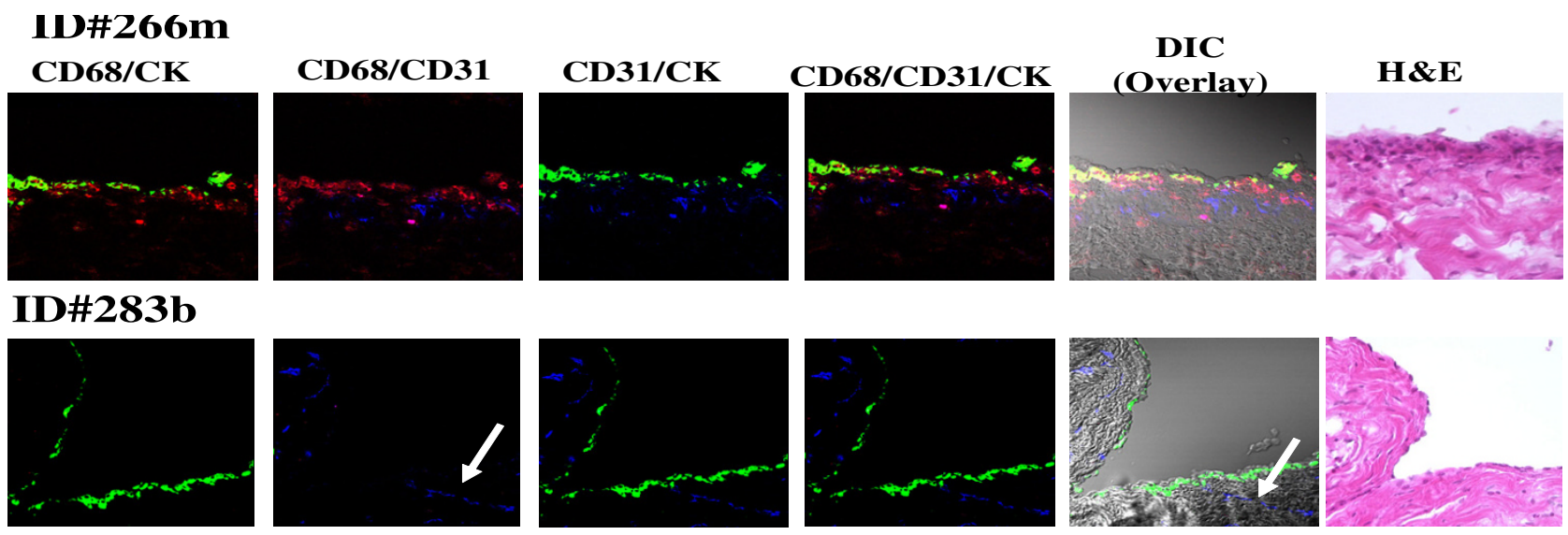

\section{ID\#235}
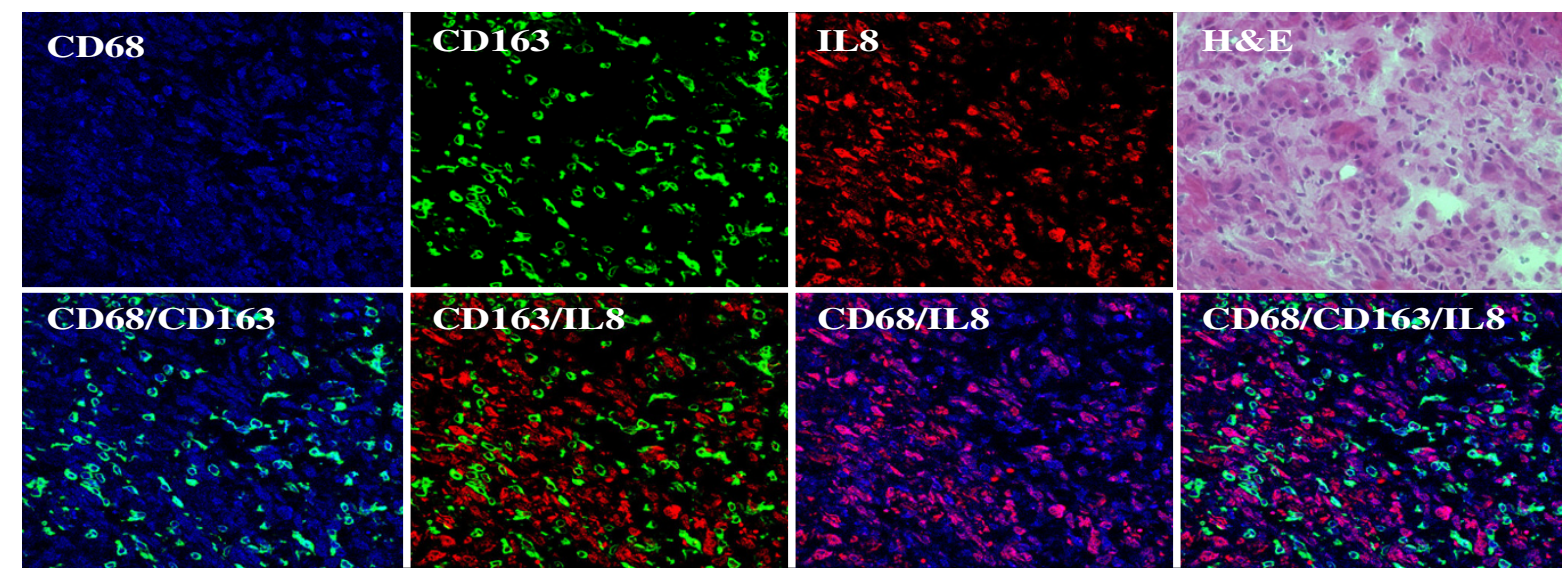

\section{Figure 3}

Triple immunofluorescence costaining of frozen right peritoneal tissues were stained with CD68 (red), CD3I (blue), and keratin (CK) (green) antibodies (Rows I \& 2) Row I, peritoneal cells from a patient with EOC (ID $266 \mathrm{~m}$ ) appear yellow from the colocalization of CD68 (red) and CK (green) on some surface mesothelial cells. CD3I staining (blue) indicates endothelial cells just under the mesothelium. Row 2, peritoneal cells from a patient with benign cystic teratoma of the ovary (ID 283b) show prominent staining for keratin in the single cell mesothelial layer but no staining for CD68 staining (red) and positive staining for endothelial cells (blue). Rows 3 and 4, peritoneal cells from patient ID\#235 showed colocalization of CD68 (blue) and CDI63 (green) appearing cyan color; CD68 (blue) and CXCL8 (red) costaining showed magenta effect and no color changed in CDI63+ cells (green). Images were analyzed by confocal laser scanning microscopy (magnification 400x). H\&E stained sections are shown for comparison.

we have shown here and elsewhere [12,21], CXCL8 appears to have a prominent role in the peritoneal and ascitic CD68+ population and specifically in CCR1+ cells. At least nine CC chemokines, many of them associated with EOC $[21,22]$, can serve as ligands for CCR1. Here we found CCR1, also highly expressed in the peritoneal microarray profile, on substantial numbers of peritoneal $\mathrm{MO} / \mathrm{MA}$ and on some T cells, suggesting that CCR1, could play an important role in migration of certain cell populations that express this receptor.

CXCL8 can be induced by various cytokines, including IL1, TNFo, IL-3, IL-13, and IL-7, most of which are produced in EOC patients and can be induced $\mathrm{H}_{2} \mathrm{O}_{2}$ and hypoxia. CXCL8 binds to CXCR1 or CXCR2, either of which can be expressed on resting $\mathrm{T}$ cells but are not usually on monocytes. We found CXCL8 to be produced on a large proportion of $\mathrm{MO} / \mathrm{MA}$ and, more variably, on $\mathrm{CD} 3+$ cells. Moreover, only a very low proportion $(<10 \%)$ of the CD68+CD163+ subset produced CXCL8. CD163 has been linked with IL-10 release in atheromatous disease [23], though in the pig, it has been associated with adaptive immunity [15]. The functional role of CD163+ MO/ $\mathrm{MA}$ in EOC is yet to be determined. 
Table 4: Proportions and mean proportions across samples for CD68+ and CD3+ mononuclear leukocytes expressing CCRI, IL-8, and VCAMI by confocal microscopy.

\begin{tabular}{|c|c|c|c|c|c|c|c|c|c|c|c|c|}
\hline \multirow[t]{2}{*}{ ANTIBODIES } & \multicolumn{8}{|c|}{ PERITO NEAL SPECIM ENS } & \multicolumn{4}{|c|}{ ASCITES } \\
\hline & TS-266 & TS-265 & TS-235 & TS-236 & TS-267 & TS-242 & TS-256 & M eans & ASC290 & ASC288 & ASC278 & Means \\
\hline CD68+/CCRI+ & 65 & 51 & 45 & 44 & 76 & 58 & 83 & 60.3 & 87 & 77 & 78 & 80.7 \\
\hline CD68+/IL8+ & 61 & 35 & 38 & 36 & 45 & 66 & 74 & 50.7 & 55 & 52 & 42 & 49.7 \\
\hline CD68+/CCRI+IL8+ & 66 & 38 & 28 & 30 & 46 & 42 & 37 & 41 & 45 & 35 & 48 & 42.7 \\
\hline CD3+/CCRI+ & 53 & 19 & 18 & 6 & 2 & 0 & 8 & 15.1 & 0 & 10 & 2 & 4 \\
\hline CD3+//L8+ & 80 & 45 & 19 & 34 & 7 & 4 & 8 & 28.1 & 0 & 10 & 2 & 4 \\
\hline CD3+/CCRI+IL8+ & 47 & 24 & 5 & 11 & 0 & 0 & 0 & 12.4 & 0 & 10 & 2 & 4 \\
\hline CD68+/CDI63+ & 19 & 38 & 31 & 43 & 67 & 39 & 78 & 45 & 30 & 36 & 91 & 52.3 \\
\hline CDI63+/IL8+ & 22 & 7 & 0 & 20 & 11 & 45 & 22 & 18.1 & 60 & 65 & 26 & 50.3 \\
\hline CD68+/CD I63+IL8+ & 5 & 3 & 0 & 9 & 4 & 22 & 19 & 8.9 & 15 & 29 & 32 & 25.3 \\
\hline CD68+/VCAMI+ & 59 & 94 & 68 & 60 & 55 & 4 & 29 & 52.7 & 79 & 81 & 26 & 62 \\
\hline $\mathrm{CD} 68+/ \mathrm{CD} 3+$ & 1 & 0 & 1 & 2 & 0 & 6 & 3 & 1.9 & 19 & 33 & 15 & 22.3 \\
\hline CD3+/VCAMI+ & 4 & 0 & 5 & 4 & 0 & 0 & 12 & 3.6 & 38 & 69 & 31 & 46 \\
\hline CD68+/CD3+VCAMI+ & 1 & 0 & 1 & 0 & 0 & 0 & 2 & 0.6 & 16 & 31 & 9 & 18.7 \\
\hline CD3/CD68 Ratio & 1 to 2 & I to II & I to 4 & I to 4 & 1 to 2 & I to 2 & 1 to 8 & & I to 2 & I to 2 & 1 to 2 & \\
\hline Disease Stage & III & III & III & III & III & II & II & & III & III & III & \\
\hline Histology & C & E & $S / E$ & $S / E$ & $S$ & S/E & $\mathrm{E}$ & & $S$ & $S$ & $S$ & \\
\hline
\end{tabular}

$\mathrm{S}=$ serous; $\mathrm{E}=$ endometriod; $\mathrm{C}$ = clear cell

Elevated levels of the pro-angiogenic chemokine CXCL8 (IL8) have been detected in a variety of tumors, including solid EOC [24] and EOC ascites fluid [25] and may promote tumor growth. Low levels have also been detected in serum of certain normal subjects, and we have observed that the single layer of mesothelium in benign pelvic disease may be positive for this cytokine (data not shown). Unpublished data from the Human Cancer Immunology Research Core Facility of M. D. Anderson Cancer Center, moreover, indicate that 8 of 40 normal donors (all females) had IL-8 levels higher than the lowest standard of $9 \mathrm{pg} / \mathrm{ml}$ (Dr. James Reuben, personal communication). These findings suggest that lower levels of CXCL8 might have a physiologic role.

Cells that produce CXCL8 in the peritoneum of patients with EOC might be expected to contribute to elevated levels of CXCL8 in the peritoneal, ascitic, and blood compartments of such patients. CXCL8 is likely to have an important role in the development or spread of EOC; it, along with vascular endothelial growth factor, has been linked with unfavorable prognosis in EOC [26]. The TNFrelated apoptosis-inducing ligand (TRAIL) can trigger apoptosis in many malignant cells [27], but CXCL8 has been shown to block TRAIL-induced cell death by converting a TRAIL-sensitive ovarian cancer cell line (OVCAR3) into a TRAIL-resistant one. CXCL8 may also regulate the expression of a member of the mitogen-activated protein kinase superfamily, p38 $\gamma$ [28] and with VEGF contribute to increased endothelial capillary functions. Lysophos- phatidic acid (LPA), a phospholipid produced from malignant ovarian epithelium, can enhance the expression of CXCL8 by tumor cells and stimulate EOC cell invasion by enhancing membrane type-1 (MT1) matrix metalloproteinase (MMP) mediated activation of MMP2 [29]. Interestingly, cPLA2, an activated enzyme involved in liberating arachidonic acid from cell membranes and dependent on MAPK-induced phosphorylation [30] was highly expressed in CD68+ cells and the CD68+CD163+ subset. p42/44 and p38 MAPK activation is required prior to translocation to the nucleus [31]. Activation of CPLA2 and other phosphorylates by cytokines in the environment of EOC may contribute to CXCL8 production. Arachidonic acid is the precursor of fatty acid derivatives, including LPA, leukotrienes, prostaglandins, thromboxanes, and other important components of the eicosanoid pathways. LPA activates several biological responses through its binding and activation of G-protein-coupled receptors, and has been detected at elevated levels in the ascites and serum of patients with EOC [32].

We might speculate that chemokines and certain cytokines could be involved in recruiting $\mathrm{MO} / \mathrm{MA}$ and certain $\mathrm{T}$ cells into the submesothelial stroma of the peritoneum, where such cells could contribute to tissue reorganization, tumor cell invasion, angiogenesis, capillary leakage, and the production of ascites.

The cytokines most often detected in serum and ascites of patients with EOC include TNF $\alpha$, IL-10, IL-6, CSF1 

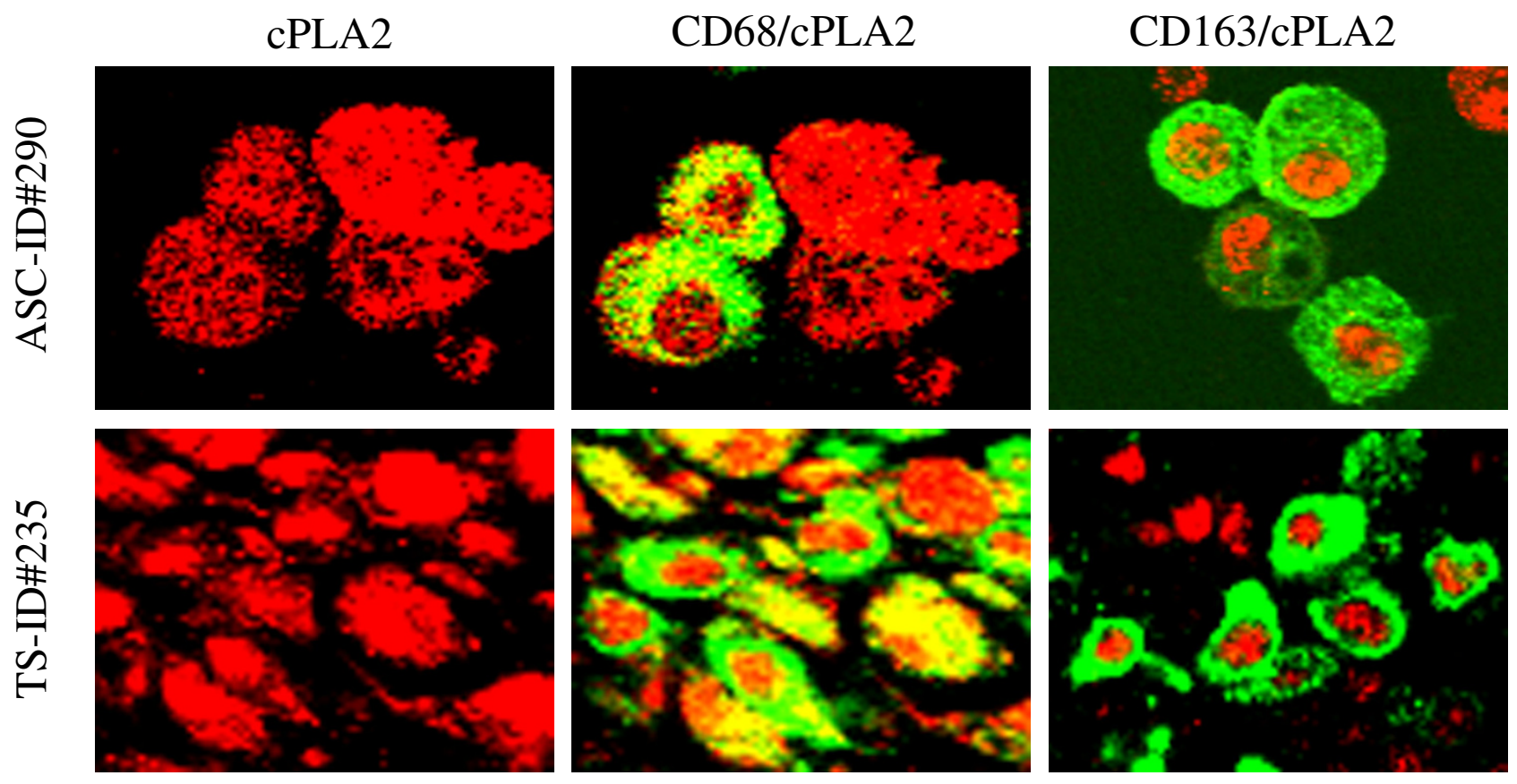

\section{Figure 4}

Stained cytospin preps of mononuclear leukocytes isolated from ascitic fluid on F:H density cushion (patient ID 290; top row) or from frozen tissue (patient ID 235; bottom row) were fixed with 4\% paraformaldehyde and double-stained with phosphocPLA2 (Ser505) antibody (red) and CD68 (green) or CDI63 (green). Indirect immunofluorescence showed pcPLA2 in both the nucleus and cytoplasm, and results were similar in the cells from ascites and those from tissue. Cells costained for CD68 and cPLA2 showed colocalization of both markers in the cytoplasm and in the nucleus (yellow). However, in CDI63+ cells, cPLA2 was seen only in relation to the nucleus.

(MCSF), IL-1, and TGF $\beta$ isotypes, all of which can be produced by activated MA [17,33-37] or by the tumor cells $[10,38]$. TNF $\alpha$ and IL- $1 \alpha$ enhance the expression of adhesion molecules on endothelial cells, thereby contributing to leukocyte attachment and migration. In our study, VCAM1 was coexpressed on both CD31+ endothelial cells and on MO/MA but not on most CD3+ cells, suggesting that the CD68+ cells and CD31+ endothelial cells in particular might be under the influence of VCAM1-sensitive cytokines released into the peritoneal microenvironment. VCAM1 is upregulated on cytokine stimulated endothelium. Such a release could be an important early step in the migration behavior of $\mathrm{MO} / \mathrm{MA}$ into the peritoneum and ascitic fluid. The presence of endothelial cells (CD31+) in proximity to and the CD68+ cells either interspersed in or just under the mesothelium, suggest that there is a close spatial relationship of peritoneal $\mathrm{MO} / \mathrm{MA}$ to ascitic $\mathrm{MO} / \mathrm{MA}$.

In summary, this study represents the first description of the inflammatory cell response in the peritoneum of patients with EOC. Our findings here support and com- plement our previous gene profiling study of the peritoneum [9]. We conclude that peritoneal MA that are separated spatially from tumor cells share several similar phenotypic characteristics and express activated gene products that could have important roles in tumor growth and metastases.

\section{References}

I. Rubin SC, Randall TC, Armstrong KA, Chi DS, Hoskins WJ: Tenyear follow-up of ovarian cancer patients after second-look laparotomy with negative findings. Obstet Gynecol 1999, 93:2I-24.

2. Dedrick RL, Flessner MF: Pharmacokinetic problems in peritoneal drug administration: tissue penetration and surface exposure. J Natl Cancer Inst 1997, 89:480-487.

3. Carter D, True L, Otis C: Serous Membranes. In Histology for Pathologists, 2nd Edition Edited by: Sternberg S. Philadelphia, Lippincott-Raven; 1997:223-239.

4. Battifora $\mathrm{H}$, McCaughey $\mathrm{W}$ : Tumors of the serosal membranes. In Atlas of tumor pathology, Third series Volume I. Edited by: Pathology UARE. Bethesda, Armed Forces Institute of Pathology; 1995.

5. Freedman RS, Deavers M, Liu J, Wang E: Peritoneal inflammation - A microenvironment for Epithelial Ovarian Cancer (EOC). J Transl Med 2004, 2:23.

6. Wang E, Marincola FM: Amplification of small quantities of mRNA for transcript analysis. In DNA arrays_amolecular cloning manual Ist ed Edited by: Bowtell D and J S. Cold Spring Harbor Laboratory, Cold Spring Harbor (NY); 2002:204-2 13. 
7. Wang E, Miller LD, Ohnmacht GA, Liu ET, Marincola FM: High-fidelity mRNA amplification for gene profiling. Nat Biotechnol 2000, I 8:457-459.

8. Wang E: RNA amplification for successful gene profiling analysis. J Transl Med 2005, 3:

9. Wang E, Ngalame Y, Panelli MC, Nguyen-Jackson H, Deavers M, Mueller P, Hu W, Savary CA, Kobayashi R, Freedman RS, Marincola FM: Peritoneal and Subperitoneal Stroma May Facilitate Regional Spread of Ovarian Cancer. Clin Cancer Res 2005, II:II3-122.

10. Gordinier ME, Zhang HZ, Patenia R, Levy LB, Atkinson EN, Nash MA, Katz RL, Platsoucas CD, Freedman RS: Quantitative analysis of transforming growth factor-beta (TGF-beta I and TGFbeta2) on ovarian carcinoma. Clinical Cancer Research 1999, 5:2498-2505.

II. Freedman RS, Lenzi R, Kudelka AP, Rosenblum M, Platsoucas CD: Intraperitoneal immunotherapy of peritoneal carcinomatosis. Cytokines, Cellular and Molecular Therapy 1998, 4:121-140.

12. Wang X, Wang E, Kavanagh JJ, Freedman RS: Ovarian cancer, the coagulation pathway, and inflammation. J Transl Med 2005, 3:25.

13. Ross DT, Scherf U, Eisen MB, Perou CM, Rees C, Spellman P, lyer V, Jeffery SS, Van de Rijn M, Waltham M, Pergamenschikov A, Lee J, Lashkari D, Shalon D, Myers TG, Weinstein JN, Botstein D, Brown $\mathrm{PO}$ : Systematic variation in gene expression patterns in human cancer cell lines. Nature Genetics 2000, 24:227-235.

14. O'Brien PC: Procedures for comparing samples wtih multiple endpoints. Biometrics 1984, 40:1079.

15. Chamorro S, Revilla C, Alvarez B, Alonso F, Esquerra A, Dominguez $\mathrm{J}$ : Phenotypic and functional heterogeneity of porcine blood monocytes and its relation with maturation. Immunology 2005, I | 4:63-7|.

16. Ordonez NG, Freedman RS, Herlyn M: Lewis and related tumorassociated determinants on ovarian carcinoma. Gynecol Oncol 1987, 26: I-10.

17. Loercher AE, Nash MA, Kavanagh JJ, Platsoucas CD, Freedman RS: Identification of an IL-I0-producing HLA-DR-negative monocyte subset in the malignant ascites of patients with ovarian carcinoma that inhibits cytokine protein expression and proliferation of autologous T cells. J Immunol 1999, 163:6251-6260.

18. Gordon IO, Freedman RS: Defective antitumor function of monocyte-derived macrophages from epithelial ovarian cancer patients. Clin Cancer Res 2006, In press:

19. Mantovani A, Sozzani S, Locati M, Allavena P, Sica A: Macrophage polarization: tumor-associated macrophages as a paradigm for polarized M2 mononuclear phagocytes. Trends Immunol 2002, 23:549-555.

20. Orre M, Rogers PA: Macrophages and microvessel density in tumors of the ovary. Gynecol Oncol 1999, 73:47-50.

21. Negus RP, Stamp GW, Relf MG, Burke F, Malik ST, Bernasconi S, Allavena P, Sozzani S, Mantovani A, Balkwill FR: The detection and localization of monocyte chemoattractant protein-I (MCPI) in human ovarian cancer. J Clin Invest 1995, 95:239I-2396.

22. Schutyser E, Struyf S, Proost P, Opdenakker G, Laureys G, Verhasselt B, Peperstraete L, Van de Putte I, Saccani A, Allavena P, Mantovani A, Van Damme J: Identification of biologically active chemokine isoforms from ascitic fluid and elevated levels of CCL I 8/pulmonary and activation-regulated chemokine in ovarian carcinoma. J Biol Chem 2002, 277:24584-24593.

23. Philippidis P, Mason JC, Evans BJ, Nadra I, Taylor KM, Haskard DO, Landis RC: Hemoglobin scavenger recepter CDI63 mediates interleukin- $I 0$ release and heme oxygenase-I synthesis: antiinflammatory monocyte-macrophage responses in vitro, in resolving skin blisters in vivo, and after cardiopulmonary bypass surgery. Circulation Research 2004, 94:119-126.

24. Ivarsson K, Ekerydh A, Fyhr IM, Janson PO, Brannstrom M: Upregulation of interleukin-8 and polarized epithelial expression of interleukin-8 receptor $\mathbf{A}$ in ovarian carcinomas. Acta Obstet Gynecol Scand 2000, 79:777-784.

25. Gawrychowski K, Skopinska-Rozewska E, Barcz E, Sommer E, Szaniawska B, Roszkowska-Purska K, Janik P, Zielinski J: Angiogenic activity and interleukin-8 content of human ovarian cancer ascites. Eur J Gynaecol Oncol 1998, 19:262-264.

26. Kassim SK, El-Salahy EM, Fayed ST, Helal SA, Helal T, Azzam Eel D, Khalifa A: Vascular endothelial growth factor and interleukin-
8 are associated with poor prognosis in epithelial ovarian cancer patients. Clin Biochem 2004, 37:363-369.

27. Wiley SR, Schooley K, Smolak PJ, Din WS, Huang CP, Nicholl JK, Sutherland GR, Smith TD, Rauch C, Smith CA, et al:: Identification and characterization of a new member of the TNF family that induces apoptosis. Immunity 1995, 3:673-682.

28. Abdollahi T, Robertson NM, Abdollahi A, Litwack G: Identification of interleukin 8 as an inhibitor of tumor necrosis factorrelated apoptosis-inducing ligand-induced apoptosis in the ovarian carcinoma cell line OVCAR3. Cancer Res 2003, 63:4521-4526.

29. So J, Navari J, Wang FQ, Fishman DA: Lysophosphatidic acid enhances epithelial ovarian carcinoma invasion through the increased expression of interleukin-8. Gynecol Oncol 2004, 95:3|4-322.

30. Boonstra J, Verkleij AJ: Regulation of enzyme activity in vivo is determined by its cellular localization. Advances in Enzyme Regulation 2004, 44:6I-73.

31. Grewal S, Morrison EE, Ponnambalam S, Walker JH: Nuclear localization of cytosolic phospholipase A2-alpha in the EA.hy.926 human endothelial cell line is proliferation dependent and modulated by phosphorylation. J of Cell Science 2002, I I 5:

32. Xu Y, Shen Z, Wiper DW, Wu M, Morton RE, Elson P, Kennedy AW Belinson J, Markman M, Casey G: Lysophosphatidic acid as a potential biomarker for ovarian and other gynecologic cancers. Jama 1998, 280:719-723.

33. Freedman RS, Edwards CL, Kavanagh JJ, Kudelka AP, Katz RL, Carrasco $\mathrm{CH}$, Atkinson $\mathrm{EH}$, Scott W, Tomasovic B, Platsoucas CD: Intraperitoneal adoptive immunotherapy of ovarian carcinoma with tumor infiltrating lymphocytes, A pilot trial. J Immunother 1994, 16:198-210.

34. Nash MA, Lenzi R, Edwards CL, Kavanagh JJ, Kudelka AP, Verschraegen CF, Platsoucas CD, Freedman RS: Differential expression of cytokine transcripts in human epithelial ovarian carcinoma by solid tumor specimens, peritoneal exudate cells containing tumor, TIL-derived T-cell lines and established tumor cell lines. Clin Exp Immunol 1998, I | 2: I72-180.

35. Moradi MM, Carson LF, Weinberg JB, Haney AF, Twiggs LB, Ramakrishnan S: Serum and ascitic fluid levels of interleukin-I, interleukin-6, and tumor necrosis factor-alpha in patients with ovarian epithelial cancer. Cancer 1993, 72:2433-2440.

36. Burke F, Relf M, Negus RP, Balkwill FR: A cytokine profile of normal and malignant ovary. Cytokine 1996, 8:578-585.

37. Berek JS, Chung C, Kaldi K, Watson JM, Knox RM, Martinez-Maza O: Serum interleukin-6 levels correlate with disease status in patients with epithelial ovarian cancer. Am J Obstet Gynecol 1991, 164:1038-1042.

38. Nash MA, Ferrandina G, Gordinier ME, Loercher AE, Freedman RS: The role of cytokines in both the normal and malignant ovary. Endocrine-Related Cancer 1999, 6:93-107.

Publish with Bio Med Central and every scientist can read your work free of charge

"BioMed Central will be the most significant development for disseminating the results of biomedical research in our lifetime. "

Sir Paul Nurse, Cancer Research UK

Your research papers will be:

- available free of charge to the entire biomedical community

- peer reviewed and published immediately upon acceptance

- cited in PubMed and archived on PubMed Central

- yours - you keep the copyright
BioMedcentral 